\title{
Data Quality Strategy Selection in CRIS: Using a Hybrid Method of SWOT and BMW
}

Otmane Azeroual (ORCID: 0000-0002-5225-389X)

German Center for Higher Education Research and Science Studies (DZHW), Berlin, Germany

E-mail: azeroual@dzhw.eu

Mohammad Javad Ershadi

Information Technology Department

Iranian Research Institute for Information Science and Technology (IranDoc), Tehran, Iran

Amir Azizi and Melikasadat Banihashemi

Islamic Azad University, Science and Research Branch, Tehran, Iran

Reza Edris Abadi

Islamic Azad University, Central Tehran Branch, Tehran, Iran

Keywords: current research information systems (CRIS), data quality (DQ), knowledge management (KM), SWOT, multi-criteria decision-making (MCDM), best-worst method (BWM)

Received: October 28, 2019

\begin{abstract}
Data quality has been considerably faced with more attention in recent years. While improving the quality of any type of information system needs to apply data quality dimensions, this process is a strategic decision of any organization. Current Research Information System (CRIS) is a state of the art information system which manages different processes for acquisition, indexing, and dissemination of researches funded by research funders. In this paper, quality improvement programs for a CRIS are strategically defined using Strength, Weakness, Opportunity and Threaten (SWOT) approach. According to examined SWOT method, weaknesses (such as failure to evaluate the quality of information contained in the research), strengths (such as the accuracy of information classification), opportunities (such as the presence of university representatives in the process of thesis/dissertation registration) and threats (such as transfer of incorrect information by other systems) are identified and categorized. Besides, data quality dimensions are considered for determining all strategies for improving CRIS. An advanced multi-criteria decision-making method called Best-Worst Method (BWM) is applied for prioritizing obtained strategies. Results of proposed methodology indicated that the development and classification of the appropriate space for recording, controlling, indexing and disseminating the received information is obtained the first rank among the other strategies. Also, the creation of a comprehensive knowledge database for all researches in different universities is another main strategy that is ranked in second priority.

Povzetek: Z metodami multikriterijskega odločanja, kombiniranja SWAT in BMW, je narejeno izbiranje najboljših strategij za CRIS, tj. za informacijske sisteme.
\end{abstract}

\section{Introduction}

In today's competitive world, information, equal to capital and human resources, is an influential factor of production and is considered as the most important relative advantage of economic enterprises. One of the features of new organizations is the over-accumulation of data, so increasing the amount of data and consequently obtained information in organizations and the need to use them in organizational decisions over the past two decades has led to the emergence of an approach called knowledge management. This necessitates the planning, organization, leadership, and monitoring of organizational knowledge, as well as the management of the process of access to the right knowledge, in order to be effective. In the current era, organizations have found that they will not survive unless they have a strategy to manage their organizational knowledge. Therefore, strategies and cycles for implementing knowledge management are evolutionally presented. On the other hand, network information systems (NIS) provide new opportunities for data quality management, which can include access to a wider range of data sources, the ability to select and compare information from different sources, to detect and correct errors, and, consequently, an overall improvement on the quality of the data. These contexts provide a wide range of evaluation techniques and data quality improvements for issues such as linkage and background, business rules, and coherent scales. Over time, these techniques evolved to counter the increasing complexity of data in information systems. Given the variability and complexity of these techniques, recent researches focus on different methods 
and strategies that help to select, customize and apply evaluation techniques and improve data quality. Recently, a newly developed information system called current research information systems (CRIS) has attracted attention and with this type of information systems, scientific organizations can provide a current scheme for their research activities and results, such as projects, thirdparty funds, patents, cooperation partners, prices and publications [1]. Furthermore, using CRIS they can manage information about their scientific activities as well as integrate them into websites [1]. Since the lack of proper information in organizations, loss of important information in the knowledge databases and the lack of full access to the important information are the main quality issues in CRIS, data quality plays an important role in the deployment process of CRIS [1]. Studies on research information management have revealed that standardization, coordination, and integration of research information is often required and challenging, but one of the main drivers for the implementation of CRIS is the benefit of integrated data collection on research information. At present, much effort has been put into collecting, integrating and aggregating research information [2]. Since different organizations are constantly requesting reports on research results, so having a uniform data model (or even a standard) for research information could simplify this request [3], [4]. Also, because of the reviewed and recommended data quality techniques (e.g., data cleansing and data profiling by [5] and [6]) that are being used in organizations lately; the application of appropriate data quality strategies is the primary concern in organizations to provide research information for strategic planning to prepare and present in a structured manner.

In this study, we therefore try to develop data quality strategies for a CRIS case using the SWOT approach (strengths, weaknesses, opportunities and threats). Due to the many varieties in the strategies and resource constraints received from organizations for the application of these strategies, an MCDM method (Multi-Criteria Decision-Making) called Best-Worst Method (BWM) is implemented to prioritize the final strategies. This combination was previously used by researchers such as [7], [8] and [9] by integrating methods such as SWOT with BWM or TOPSIS (technique for order preference by similarity to the ideal solution) to achieve the desired results.

The next subsection tries to further introduce the contribution of the current study.

\subsection{Contribution of study}

Although in some previous studies strategic management has been considered as the main tool for quality improvement in information systems [10], extending this approach to CRIS is a state-of-the-art work. In addition, the combination of this approach according to data quality dimensions and the development of strategies with regard to data quality principles have rarely been investigated [11] [12]. Because of the importance of CRIS as the main category of information systems, this paper therefore provided a SWOT framework to improve the effectiveness of these systems. Due to different data quality dimensions and successively defined strategies, a newly developed MCDM approach is applied to prioritized strategies.

The structure of this paper is as follows. In the next section, background works are introduced. Then in section (3), the methodology of current research is developed. After that, in section (4), the case in which the current research is done is described. In section (5) the main finding of the research is showed. Finally, the discussion and conclusions are provided in section (6).

\section{Literature review}

Since strategies for improving data quality in the current research information system (CRIS) in the proposed case are inspired by the principles of knowledge management, this section first provides a brief history of the framework for knowledge management. Next, the principles of CRIS and the quality of the data are discussed during the integration of scientific works (such as theses and dissertations), research projects, etc. into CRIS. Through data integration, quality problems can be identified and necessary improvements made. The data quality dimension is then described to provide a framework for the appropriate definition of strategies. Finally, the SWOT method (strengths, weaknesses, opportunities and threats) is presented as a well-known approach to defining strategies.

\subsection{Knowledge management}

A large number of studies on information systems (IS) have proven the importance of knowledge in the organization [13]. These researches declare that knowledge is more valuable than other assets in the organizations; consequently, it needs to be managed more efficiently. Knowledge Management (KM) has become a prevalent research trend in academia and the business sector [14]. KM is defined as "the process of capturing, storing, sharing, and using knowledge" [15]. Besides, KM is an emerging mechanism that can find particular information more efficiently and organize that information for quick retrieval and reuse [16]. KM can be one of the fundamental approaches of modern institutions as it can lead to the maintenance, growth, success, and innovation of the organization [17]. There are several methods of KM from the perspective of researchers. [18] believes that knowledge management processes include knowledge creation, knowledge transfer, and the application of knowledge. [19] pointed out that KM processes include knowledge gathering, knowledge transfer, and the use of knowledge. [20] and [21] pointed out that $\mathrm{KM}$ processes include knowledge acquisition/creation, knowledge sharing/dissemination, and knowledge utilization. [21] has determined that KM processes are working in a continuous cycle, in which, it enables the information systems users to achieve their goals, add a piece of new knowledge and share that knowledge accordingly. One way of evaluating KM processes is whether it is possible to deepen the subject. 


\section{Important steps on the development of knowledge management}

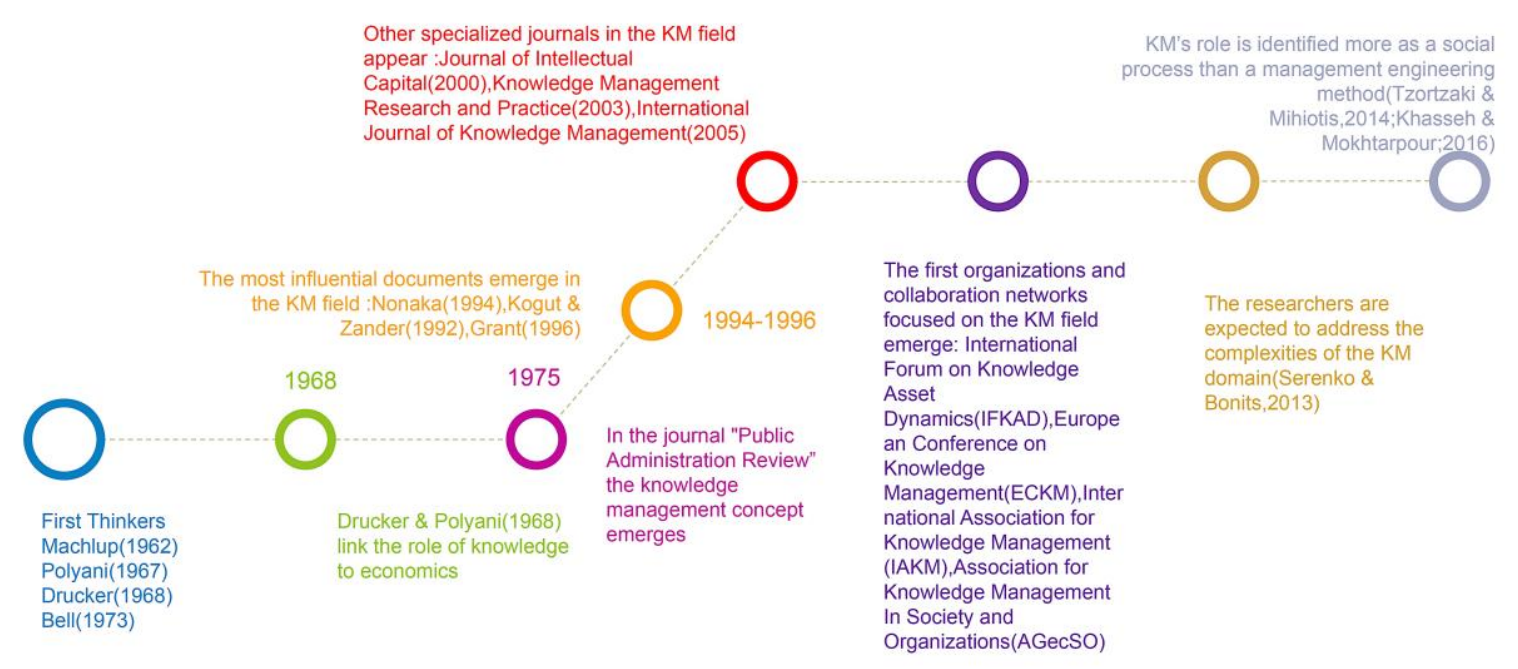

Figure 1: Significant events in development of the KM.

The question we have to answer is: How important are databases for scientific production? [22]. Existing databases make explicit knowledge stored and accessible, and since dynamic knowledge is constantly evolving, robust and flexible knowledge management systems are essential to receive frequent updates from all parts of the organization. The access routes must be classified precisely and consciously both as a key word and as key terms for those seeking knowledge [23]. KM processes are considered as the fundamental processes for the successful adoption and implementation of a new IS [24], [25] [26]. Also, IS can be employed to leverage the KM processes of acquiring, storing, sharing, and applying a particular knowledge [27]. The main KM processes are knowledge discovery, knowledge capture, knowledge sharing and knowledge application. Besides, [28] demonstrated that information technologies could serve as a facilitator of KM. Based on this literature, which is briefly shown in Figure 1, it is assumed that KM is mainly related to the support of information system processes and that $\mathrm{KM}$ as a scientific area is much more than just supporting the development of IS.

This paper examines in a CRIS which is implemented for the exchange and dissemination of knowledge for all researchers. In this regard, the next subsection is devoted to a brief explanation of CRIS.

\subsection{CRIS}

Access to information about current research activities and their results across Europe is an essential prerequisite for the success of EU innovation policy [49]. That is why the CRIS was developed and is the most important reporting instrument for research-based funding [50]. CRIS or research information systems (RIS), scientific information systems (SIS), alike enterprise information systems (EIS), should cover interdisciplinary aspects as a dimension that influences significantly research potential and activity of particular scientists. A CRIS is a specialized database or federated information system to collect, manage and provide information on research activities and results [1]. In addition, the CRIS is said to be a useful tool for researchers and research institutions by providing a range of services, such as: For example, simplifying the administrative routines for researchers and widespread reuse of the high-quality data registered in the CRIS [50]. Further literature on the term CRIS can be found on the CRIS Repository website (https://dspacecris.eurocris.org/). The structure and functionality of CRIS could be divided into three layers according to [1] as follows:

1. The data access layer contains the internal and external data sources, e.g., operational databases (human resources, finance, project management and etc.), open repositories, identifiers (ORCID, DOI, etc.), bibliographic data from the Web of Science, Scopus or PubMed, etc. This layer includes data models for the standardized collection, provision, and exchange of research information, such as the Research Core Dataset (RCD) and the Common European Research Information Format (CERIF). The integration of these data sources into the CRIS takes place via classical Extract, Transform and Load (ETL) processes.

2. The application layer (backend) contains the CRIS and its applications, which merge, manage and analyze the data held at the underlying level.

3. The presentation layer (frontend) shows the target group-specific preparation and presentation of the analysis results for the user, which are made available in the form of reports using business intelligence tools, via portals, websites, etc.

CRIS is becoming increasingly important at European and international universities. Therefore, the special features of CRIS can be explained to make the differences to the other information systems clear. CRIS can combine the university's internal systems such as personnel, student administration, finance and price management systems as 
well as a variety of external data sources, including premade researcher profiles via Profile Refinement Services, as well as existing data on a single platform. Researchers, administrators, and delegates enter data only once, and staff across the university use the information in CRIS for a variety of purposes. CRIS offers other special features as follows:

- CRIS offers the institution a comprehensive overview of the activities, specialties and achievements of its researchers.

- CRIS can also search external data sources (e.g. Scopus, WoS, PubMed, arXiv, CrossRef, Mendeley, etc.) to determine the results of researchers at their institution. CRIS automatically retrieves the metadata and saves researchers time and effort.

- CRIS makes it easier to create, update and correct researcher profiles by automatically retrieving publication lists from relevant internal and external databases.

- With CRIS, CVs for different requirements can be created at the push of a button and then exported as Word or PDF files or published online.

- CRIS supports universities and their scientists in their search for research opportunities, research sponsors and mentors, etc.

- With the CRIS, universities can find internal and external cooperation partners.

- Much more.

In the next subsection data quality dimensions besides basic strategies for improving data quality are introduced.

\subsection{Data quality (DQ)}

The research carried out on semi-structured and unstructured events in the DQ domain indicates a strong historical connection between the DQ and the database design [16]. Even complete DQ procedures have bias but their focus is on a set of structured data that provides the most information sources in organizations [12]. Nowadays, switching to semi-structured data and the lack of structure as a corporate information resource is far more common. Also, DQ techniques for semi-structured and unstructured data have recently been investigated. Improving DQ techniques for unstructured and semistructured data in these domains requires a higher degree of interpersonal communication [29]. The efficacy of scientific data collection and validation processes has always been debated. Traditional approaches are likely to result in poor quality scientific data being recorded [30]. As a result, the scientific results that are mostly based on these data are also of poor quality, and even if the data collection and validation steps are performed correctly, the processes performed are not always qualitatively documented in the scientific paper. This leads to not only a very difficult understanding of scientific literature, but also scientific studies that are difficult to reproduce. This lack of reproduction has been led to a growing concern in various research areas [31], [32], [33]. However, attention to the reproducibility of IS research has so far been limited [34]. Also, the relationship between data quality and process quality is due to the linkage and variety of features of business processes in organizations [35], covering a large part of the research. Different effects of data quality have been investigated in three levels of operational, tactical, and strategic levels in research [16]. Quality of data and its relevance to the quality of services, products, business operations and consumer behavior are widely discussed in the general terms [36], [37]. In these studies, general statements such as "the quality of a company's information is positively related to firm performance" was based on empirical evidence. Also, the issue of how improving information production processes positively affects data and the quality of information has also been analyzed. In the process of improvement, each of the different methods can adopt two general strategies as follows [16]:

1. Data-driven strategy

2. Process-driven strategy

Data-driven strategies improve data quality by directly modifying the value of data. For example, the quality of the data is improved by updating them from another database and replacing them with updated data. Process-oriented strategies also improve quality by redesigning processes that create or modify data. For example, one can redesign a process by including activities that control the data format before storage [38]. Data-centric and process-oriented strategies implement various types of techniques, such as algorithms, intelligent technologies, and knowledge-based activities, aimed at improving data quality. A list of improvement techniques related to strategy-based approaches is as follows:

1. Access to new data, which improves the old data and gets higher quality, and this technique is used instead of methods that cause quality problems in the data.

2. Standardization (or normalization) that replaces or completes non-standard data values with values that conform to the standard. For example, the nickname is replaced by the original name. For example, Bob with Robert, and abbreviations corresponding to the full name are replaced.

3. The history link, which identifies the display of information in two (or several) tables that may refer to the same entity in the real world.

4. Integrating data and designs, which provides an integrated view of the information provided by heterogeneous data sources. The main purpose of integration is to provide a user with access to data stored in heterogeneous data sources and through the integrated view of these data.

According to theory, our data processing consultancy offers a new solution to improve data quality at an early stage, including condition analysis, software design, software implementation and data integration through data consultancy. To construct a framework for the rule-based measurement of IS research data quality, we start from the seven aspects or seven W's of scientific data collection and validation identified by [39] as follows:

1. What explains exactly what is captured in the data.

2. When refers to the time at which the data are collected. 


\begin{tabular}{llll}
\hline Intrinsic & Accessibility & Contextual & Representation \\
\hline Accuracy & Accessibility & Relate & Interpretability \\
Objectivity & Security & Value Added & Ease of understanding \\
Belief & & Up to date & Compatible display \\
Confidence & & Comprehensiveness & \\
& & Data amount & \\
\hline
\end{tabular}

Table 1: Data quality dimensions [41].

3. Where refers to the location (virtual or real) where the data are collected.

4. How describes the precise process(es) of data collection.

5. Who details the individual(s) involved in the data collection.

6. Which details the instruments or artifacts used in collecting the data.

7. Why provides the set of reasons or goals for collecting the data.

Failure to properly implement each of these seven aspects reduces the quality of the research data [33]. Data quality depends largely on the organization of the information system and how it is processed. Then, measuring and improving data quality in organizations are complex tasks. Hence, to assess the quality of metadata, it is required to employ a standard structure. In this paper, we not only use the four data quality dimensions (completeness, correctness, consistency, and timeliness) in the context of CRIS [40], but also focus on the dimensions used by [41]. These dimensions are accuracy, objectivity, reliability, authenticity, relevance, value-added, update, comprehensiveness, amount of data, interpretability, ease of perception, concise presentation, consistent display, availability, and security. Besides, they are categorized into four categories: intrinsic, contextual, representation, and accessibility. Theses category are shown in the following Table 1. Therefore, identifying appropriate executive policies for improving the data quality of CRIS at hand needs to define suitable KM strategies in the context of DQ dimensions. In the next subsection, a framework called SWOT is introduced for this aim.

\subsection{SWOT}

SWOT Analysis is a tool used for strategic planning and strategic management in organizations. It can be used effectively to build organizational strategy and competitive strategy. In accordance with the System Approach, organizations are in interaction with their environments and comprised of various sub-systems.

So, an organization communicates with two environments, first its inside and the second its outside. It is a necessity to analyze these environments for strategic management practices. This process of examining the organization and its environment is termed SWOT Analysis. SWOT analysis is a simple but powerful tool for sizing up an organization's resource capabilities and deficiencies, its market opportunities, and the external threats to its future" [42]. The acronym SWOT stands for 'strengths', 'weakness', 'opportunities' and 'threats'. SWOT analysis is a strategic planning framework used in the evaluation of an organization, a plan or a project. SWOT Analysis has two aspects: internal and external. Internal aspect consists of organizational factors, also strengths and weaknesses, while external aspect consists of environmental factors, also opportunities and threats. Strengths and weaknesses are internal factors and attributes of the organization, opportunities and threats are external factors and attributes of the environment [43]. On the context of CRIS based on some main researches such as [44] and [45] the following general structure of SWOT could be achieved.

The strengths of CRIS are:

- Easy access to information regarding research activities

- Research activities are supported and optimized

- It is possible for researchers to manage their own activities

- Administration of the data takes less time

- Information is stored in a system and in a database

- Effective data usage

- Easy retrieval for prospects and cooperation partners of persons and contact information, research activities and services

- Clear presentation of a research profile

- Auxiliary function in the creation of e.g. CVs and publication lists

- Finding and sharing research information

- Research activities can be represented graphically by analysis and visualization function

The weaknesses of CRIS

- Introduction of CRIS means high financial and time expenditure

- Furthermore, there are several sources regarding the query

- Several entries necessary

- Scattered information

- Data is publicly available, even if it is only stored in the background

\section{The opportunities of CRIS}

- As consistent as possible, so comparisons and assessments can be made quickly and easily

- Supporting the design and selection of a CRIS by standardization, so that more benefits arise, such as data exchange

- Collaborations between scientists or departments should be analyzed in order to find out in which areas these cooperation's exist

The threats of CRIS 

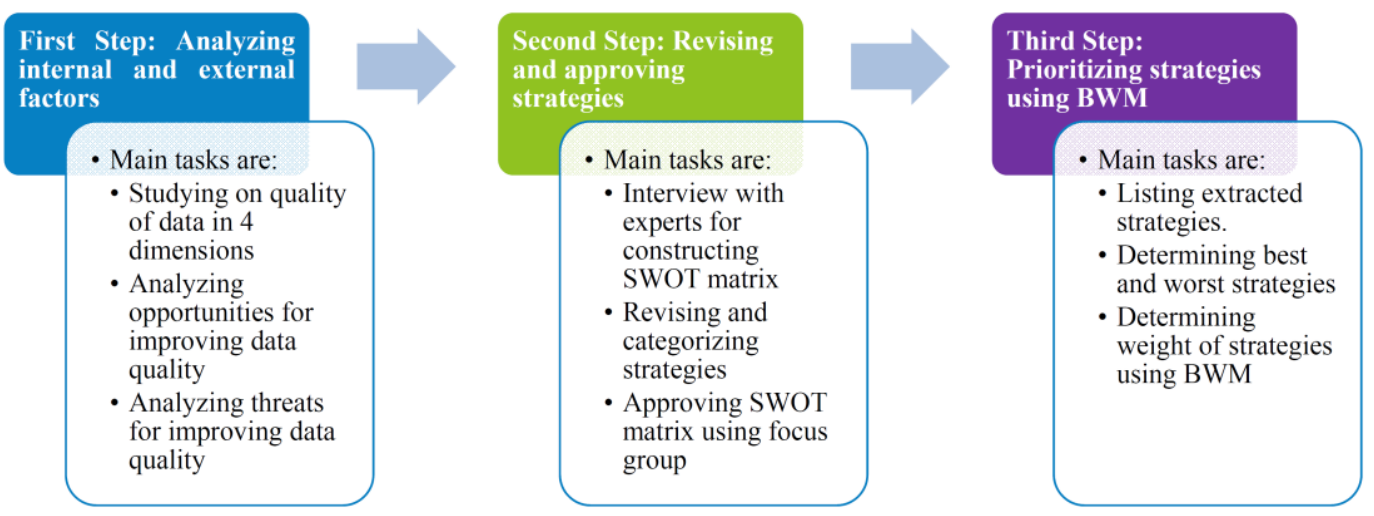

Figure 2: The methodology of the current study.

- Compatibility and interoperability of different CRIS data - different standardizations

- Research institutions and universities are able to develop their own CRIS

- Open source solutions can be used as an alternative to CRIS

After giving an overview of the SWOT analysis in the context of CRIS, the purpose of the present research is to answer the following questions:

1. What are the opportunities and threats and the strengths and weaknesses of the organization in the use of data quality of information systems?

2. What are the effective strategies in the information system of CRIS?

To answer these questions, the brainstorming method was used, which was derived from five experts who were CRIS and data quality professions (these are CRIS managers interviewed). CRIS managers have to do an important balancing act in day-to-day business: It is important to pursue well-founded strategies, which, however, can be adjusted just as dynamically if influencing factors change. In order to master this challenge, SWOT analysis is often used as a means of strategy generation. It is ideal for the development of various strategies. The aim of our SWOT analysis is to derive the appropriate measures for more success from the use of CRIS. The SWOT research has shown that most universities spend a lot of money, time and nerves to eliminate weaknesses and often spend themselves or get bogged down in the process.

The structure of main steps for finding best DQ strategies of CRIS with high priorities is described in the next section.

\section{Methodology}

This research is executed of the following 3 main steps as are shown in Figure 2. In the first step after studying the quality of data in different four dimensions, complete analysis on inside and outside of the organization is done.
In this regard, opportunities for improving the quality of data and threats which have main effects on quality are determined. Then, in the second step, the internal and external factors are revised and approved through an interview with experts. SWOT matrix is constructed and finalized in this step using a focus group. Finally, in the third step, all strategies are ranked using the BWM method. The strategies with high importance are obtained in this step.

According to the research methodology, in this research five experts from the organization which were professions in CRIS and data quality framework have been consulted. Their expertise was data quality, information science, and information system design. For analysis of data in BWM techniques have been and the used software was Lingo ${ }^{1}$.

\subsection{The Best-Worst Method}

In this section, the steps of the BWM method [46] which have been used to gain weight of each criterion is described.

Step 1: Specify the set of criteria: In this step, we consider the criteria $\{\mathrm{C} 1, \mathrm{C} 2, \ldots, \mathrm{Cn}\}$ to be used in decision making.

Step 2: Identify the best (in other words, the most desirable and most important) and the worst (the most unfavorable and the least important) criteria. In this section, the decision-maker generally outlines the best and worst criteria.

Step 3: Determining the performance of the best criterion against other criteria using numbers from 1 to 9 . The best criteria for the other criteria may be as follows:

\section{Eq.1}

$A_{B}=\left(a_{B_{1}}, a_{B_{2}}, \ldots, a_{B_{n}}\right)$

Which $a_{B_{j}}$ specifies the performance of the best B criterion relative to the $\mathrm{j}$ criterion. Obviously $A_{B_{b}}=1$. For example, this vector represents the performance of the price benchmark against other criteria.

\footnotetext{
${ }^{1}$ https://www.lindo.com/index.php/products/lingo-andoptimization-modeling
} 


\begin{tabular}{lccccccccc}
\multicolumn{1}{c}{$\mathbf{a}_{\mathbf{B}_{\mathbf{w}}}$} & $\mathbf{1}$ & $\mathbf{2}$ & $\mathbf{3}$ & $\mathbf{4}$ & $\mathbf{5}$ & $\mathbf{6}$ & $\mathbf{7}$ & $\mathbf{8}$ & $\mathbf{9}$ \\
$\begin{array}{l}\text { Consistency } \\
\text { Index }(\boldsymbol{m a x} \boldsymbol{\xi})\end{array}$ & 0.00 & 0.44 & 1.00 & 1.63 & 2.30 & 3.00 & 3.73 & 4.47 & 5.23
\end{tabular}

Table 2: Compatibility rate.

Step 4: Specify the performance of all criteria against the worst-case using numbers from 1 to 9. The results of comparisons of criteria to the worst-case criteria can be as follows:

\section{Eq.2}

$A_{W}=\left(a_{1_{w}}, a_{2_{w}}, \ldots, a_{n_{w}}\right) T$

$a_{j_{w}}$ represents the performance of criterion $\mathrm{j}$ versus the worst $\mathrm{W}$ criterion. Obviously, the value $A_{W_{w}}=1$. For example, our view is that this vector represents the performance of all criteria relative to the appearance criterion.

Step 5: Find the optimal weights $\left(w_{1}{ }^{*}, w_{2}{ }^{*}, \ldots, w_{n}{ }^{*}\right)$

The optimal values for the unique criteria are for each pair of $W_{B} / W_{J}=a_{B_{j}}$ and $W_{J} / W_{W}=a_{j_{W}}$.

To satisfy these conditions for all $\mathrm{j}$, we need to find a solution that minimizes the magnitude of the maximum difference between $\left|W_{B} / W_{J}-a_{B_{j}}\right|$ and $\left|W_{J} / W_{W}-a_{j_{w}}\right|$.

Given that the weights are non-negative and admissible; the following problem can be expressed in the non-linear model according to formula 3 :

Eq.3 Min $\max \left\{\left|W_{B} / W_{J}-a_{B_{j}}\right|,\left|W_{J} / W_{W}-a_{j_{w}}\right|\right\}$ S.t

$\Sigma_{j} W_{j}=1$

$W_{j} \geq 0$, for all $\mathrm{j}$

The above problem can be expressed in formula 4 :

Eq.4

Min $\varepsilon$

s.t

$\left|W_{B} / W_{J}-a_{B_{j}}\right| \leq \varepsilon$, for all $\mathrm{j}$

$\left|W_{J} / W_{W}-a_{j_{w}}\right| \leq \varepsilon$, for all $\mathrm{j}$

$\Sigma_{j} W_{j}=1$

$W_{j} \geq 0$, for all $\mathrm{j}$

And this is converted into a linear model in formulas 5 which makes it easier to compute:

Eq.5

Min $\max \left\{\left|W_{B}-a_{B_{j}} W_{J}\right|,\left|W_{J}-a_{j_{w}} W_{W}\right|\right\}$

The above problem can be expressed using the formula 6 as follows:

Eq.6

$\operatorname{Min} \xi^{L}$

s.t

$\left|W_{B}-a_{B_{j}} W_{J}\right| \leq \xi^{L}$, for all j

$\left|W_{J}-a_{j_{w}} W_{W}\right| \leq \xi^{L}$, for all $\mathrm{j}$

$\Sigma_{j} W_{j}=1$

$W_{j} \geq 0$, for all $\mathrm{j}$
By solving the above equation, we obtain the optimal values of the weights $\left(w_{1}{ }^{*}, w_{2}{ }^{*}, \ldots, w_{n}{ }^{*}\right)$ and the value of $\varepsilon^{*}$. Then, using $\varepsilon^{*}$, we introduce a compatibility rate. It will be clear that larger values for $\varepsilon^{*}$ will result in higher compatibility rates and lower reliability of the comparisons.

\subsubsection{Calculation of compatibility rate}

In this subsection, a consistency ratio is proposed for the BWM to check the reliability of the comparisons. For each criterion $\mathrm{j}$, a comparison will be perfectly consistent when $a_{B j} \times a_{j W}=a_{B W}$, where $a_{B j}, a_{j W}$, and $a_{B W}$ represent the performance of best criterion related to criterion $j$, criterion $\mathrm{j}$ related to worth criterion, best criterion related to worth criterion respectively [46]. Since the proposed BWM may not be fully compatible with some $\mathrm{j}$ we used the compatibility rate to evaluate possible inconsistency. To do this, we compute the lowest compatible value of comparison as follows.

The set $a_{i j}=\left\{1, \ldots, a_{B W}\right\}$ indicates that the highest possible value for $a_{B W}$ is 9 . The compatibility value decreases when $a_{B j} \times a_{j w}$ is less or more than $a_{B W}$, or the equation $a_{B j} \times a_{j w} \neq a_{B W}$ is established. In other words:

Eq.7

$\left(\mathrm{a}_{\mathrm{B}_{\mathrm{j}}}-\varepsilon\right) \times\left(\mathrm{a}_{\mathrm{j}_{\mathrm{w}}}-\varepsilon\right)=\left(\mathrm{a}_{\mathrm{B}_{\mathrm{w}}}+\varepsilon\right)$

As stated above, at least the compatibility is when $\mathrm{a}_{\mathrm{B}_{\mathrm{W}}}$ $=\mathrm{a}_{\mathrm{B}_{\mathrm{j}}}=\mathrm{a}_{\mathrm{j}_{\mathrm{w}}}$. Thus, we have:

$$
\begin{aligned}
\left(\mathrm{a}_{\mathrm{B}_{\mathrm{j}}}-\varepsilon\right) \times & \left(\mathrm{a}_{\mathrm{j}_{\mathrm{w}}}-\varepsilon\right)=\left(\mathrm{a}_{\mathrm{B}_{\mathrm{w}}}+\varepsilon\right) \\
& \Rightarrow \varepsilon^{2}-\left(1+2 \mathrm{a}_{\mathrm{B}_{\mathrm{w}}}\right) \varepsilon+\left(\mathrm{a}_{\mathrm{B}_{\mathrm{w}}}{ }^{2}-\mathrm{a}_{\mathrm{B}_{\mathrm{w}}}\right) \\
& =0
\end{aligned}
$$

Solving this equation for $\varepsilon$ lead we to the maximum value of $\varepsilon$ as indicated in the Table below.

Then we get the compatibility rate value using $\varepsilon^{*}$ from Table 2 and its compatibility index using formula 9. Based on equation 9 if the compatibility rate falls in the appropriate region then the proposed BWM is verified.

Eq.8

$$
\text { Compatibility rate }=\frac{\varepsilon^{*}}{\text { Compatibility Index }}
$$

In the rest of this paper, based on case study strategy for improving data quality obtained and using BWM are ranked.

\section{Case study}

This paper uses the pre-defined methods to determine and evaluate the main data quality strategies of CRIS. CRIS is considered as online dissemination system for Iranian 
theses and dissertations (GANJ) ${ }^{2}$ and the largest national scientific treasure. In addition, CRIS is the reference of many researchers around the world. GANJ was developed for Iranian metadata of scientific research (such as publications, patents, projects, etc.). It hosts over 10,000 users who perform tens thousands of searches a day (i.e. around 10,000 unique IP-based users).

In this work, the main processes of CRIS are examined and documented. Existing processes in CRIS are divided into three general sections, each referred to as (i) acquisition and registration of scientific document; (ii) indexing and (iii) dissemination.

1. Acquisition and registration process

Inputs of acquisition and registration of scientific document processes in the CRIS are metadata for scientific works (e.g. theses, dissertations, etc.), research projects and government reports. This process includes quality control operations implemented in all fields of metadata.

2. Indexing process

The providing information process includes the preparation of documents and records of information. Quality control operations will be implemented in all of these subsections and processes mentioned for ensuring the validity of information in the system.

3. Dissemination process

Editing metadata received from the indexing process and assigning a unified code to each record is done in this process. Overview of bibliographic information is reviewed too. If there is no problem, the document is approved and disseminated. The main role of this process is storage and dissemination of metadata, but any quality problem is identified that record would be returned to the indexing unit.

In this research using SWOT, while considering data quality dimensions, the main strategies for augmenting the quality of data are defined. Then the proposed strategies are ranked based on the BWM method.

The finding of this research is described in the next section.

\section{Findings}

Given the importance of data quality in the KM process, it is necessary to review the strategies in accordance with the knowledge transfer hierarchy in the organization. In order to determine the strategies for improving the quality of data in knowledge management, SWOT analysis with BWM has been used. So, according to three main stages of this research which are introduced in section 3, external and internal environment are analyzed and the controllable and uncontrollable sub-factors that affect different dimensions of data quality are identified. To comprehensively implement this stage, as was explained in the section 2, the brainstorming method was employed to do SWOT analysis based on expert's judgments. For better classifying the obtained SWOT, each analysis was done based on data quality dimensions according to Table 1 and the results of are shown in Table 3. Then, based on stage 2 of methodology which was explained in Figure 2 using SWOT sub-factors and finally the SWOT matrix and strategies were formed (see Table 4). The concept of SO strategy is the proper use of opportunities by exploiting the strengths of the organization. The WO strategy seeks to exploit appropriate environmental opportunities in light of the organization's weaknesses. ST strategy is also related to reducing or eliminating the effects of environmental threats through the optimum use of the strengths of the organization. Finally, the WT strategy, taking into account the organization's weaknesses, reduces the effects of environmental threats. The final result after approving experts is shown in Table 4.

In the last sub-step of the stage 2, according to the information gathered from the experts and using focus group method, SWOT components as are shown in Table 4 were verified. In other words, as is demonstrated in Table 4, four basic criteria for formation of data quality strategies on CRIS to respond the first question of our research, are opportunities, threats, weakness and strength.

In the third stage, according to the identification of the organization's strategies, we will rank the strategies, which its result will be shown using the following five steps based on the BWM technique.

Step 1: Determine a set of decision criteria.

Step 2: Determine the best (most desirable, most important) and worst (the most unfavorable, least important) criterion.

In this section, according to an opinion poll from the organization's experts, $\mathrm{W}_{1}$ and $\mathrm{W}_{9}$ policies were also evaluated and introduced as the best and worst policy.

Step 3: Determine the importance of the best benchmark against other criteria (see Table 6).

Step 4: Determine the importance of other criteria to the worst criterion (see Table 7).

Step 5: Determine the optimal weight.

Relationship among criteria is constructed based on model (4) as follows:

Min $\varepsilon$
s.t
$\left|W_{1}-3.6 W_{2}\right| \leq \varepsilon$
$\left|W_{1}-4.2 W_{3}\right| \leq \varepsilon$
$\left|W_{1}-3 W_{4}\right| \leq \varepsilon$
$\left|W_{1}-5.4 W_{5}\right| \leq \varepsilon$
$\left|W_{1}-4.8 W_{6}\right| \leq \varepsilon$
$\left|W_{1}-6.2 W_{7}\right| \leq \varepsilon$
$\left|W_{1}-4 W_{8}\right| \leq \varepsilon$
$\left|W_{1}-4.6 W_{9}\right| \leq \varepsilon$
$\left|W_{1}-4.8 W_{10}\right| \leq \varepsilon$
$\left|W_{1}-4.4 W_{11}\right| \leq \varepsilon$
$\left|W_{1}-4.2 W_{12}\right| \leq \varepsilon$
$\left|W_{1}-4 W_{13}\right| \leq \varepsilon$


$\mathrm{W}_{1}+\mathrm{W}_{2}+\mathrm{W}_{3}+\mathrm{W}_{4}+\mathrm{W}_{5}+\mathrm{W}_{6}+\mathrm{W}_{7}+\mathrm{W}_{8}+\mathrm{W}_{9}+\mathrm{W}_{10}+\mathrm{W}_{11}+\mathrm{W}_{12}+\mathrm{W}_{13}=1$

$\mathrm{W}_{1}+\mathrm{W}_{2}+\mathrm{W}_{3}+\mathrm{W}_{4}+\mathrm{W}_{5}+\mathrm{W}_{6}+\mathrm{W}_{7}+\mathrm{W}_{8}+\mathrm{W}_{9}+\mathrm{W}_{10}+\mathrm{W}_{11}+\mathrm{W}_{12}+\mathrm{W}_{13} \geq 0$

\begin{tabular}{ll}
\hline Strategies & Identified factors \\
\hline $\begin{array}{l}\text { Opportunities } \\
\text { outside the }\end{array}$ & 1. Accuracy \\
organization & Use Auto-Text Correcting Techniques based on the Deep Learning method \\
& The presence of university representatives in the process of registering theses/dissertations \\
& 2. Objectivity \\
Use of knowledge of the other experts out of the organization in the development of the system \\
Study the effect of data quality in future research \\
3. Believability \\
Creating a competitive development of knowledge management software \\
The use of data analysis institutes in the development of information quality \\
4. Validity
\end{tabular}

Assessing the reputation of external information sources by universities and higher education institutions

Identification of successful organizations in the field of data quality

\section{Availability}

Use valid external available resources

\section{Security}

The use of modern information protection technologies

The use of rival strategy to create internal information security

\section{Relevancy}

Development of technologies of software provider companies

Establishing necessary information infrastructure in the country

\section{Value Added}

Use of software and data mining analytics for better presentation and dissertation development

\section{Being up to date}

Knowledge-based development in the evaluation of data quality

Use of new technologies in converting transferable data in organizational references

\section{Comprehension}

Development of operational levels of authoritative scientific and operational references

Establishing necessary infrastructure at universities

\section{The amount of data}

Establishing small scientific bases at educational institutions

The motivation of competitors using data quality approaches

Create infrastructure to get all useful information

\section{Interpretability}

Provide training on personnel for augmenting information quality

Simplifying information in main resource tanks

\section{Ease of understanding}

Create new search engines in non-organizational resources

Creating ease of access and understanding infrastructures in rival booths

\section{Concise presentation}

Indexing information on rival information

\section{Compatible display}

Assessing rival approaches to access information for the audience 


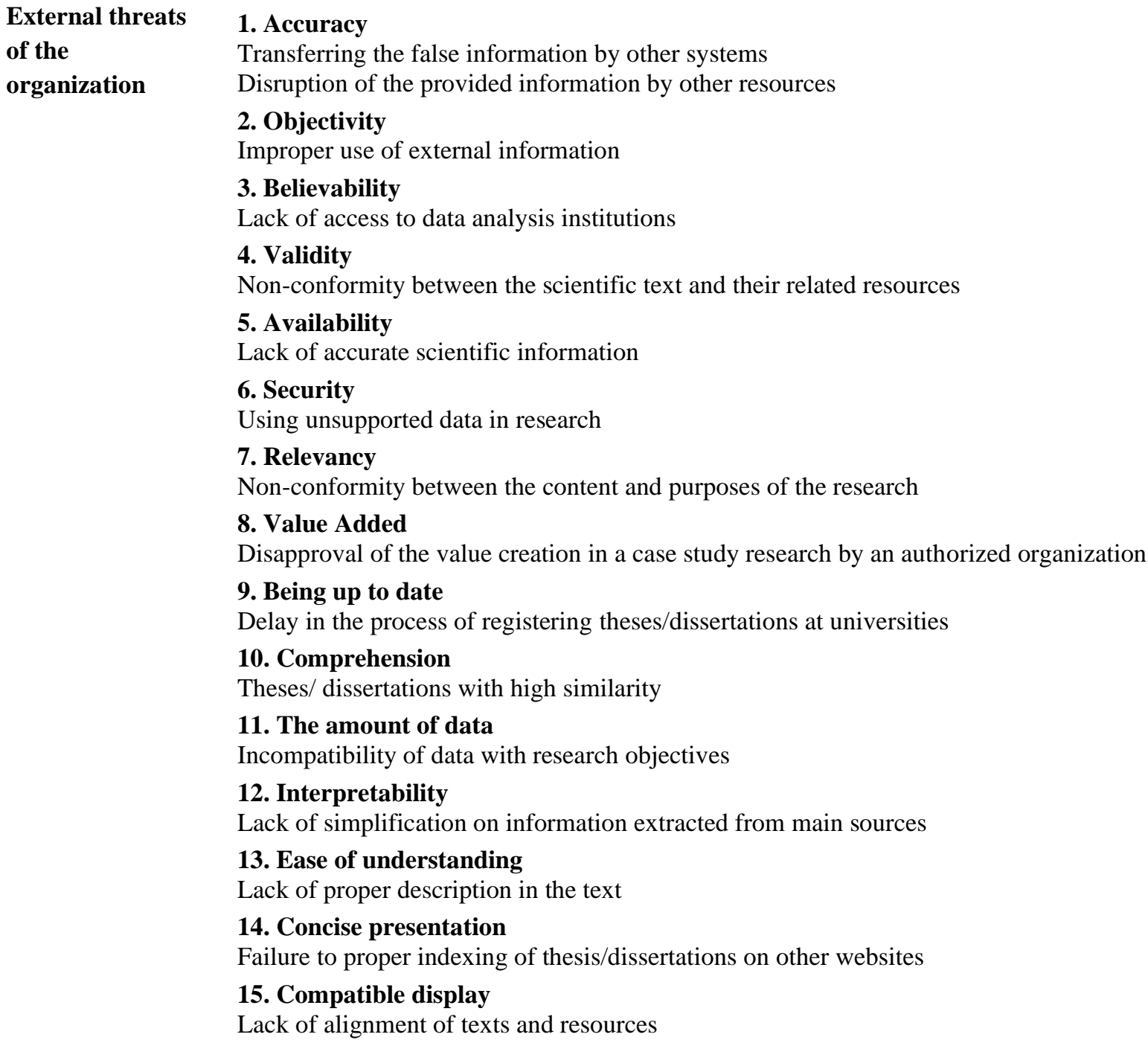

\section{Internal organization strengths}

\section{Accuracy}

Accuracy in information classification

Accuracy in the amount of information used Improve the process of registering theses/dissertations

2. Objectivity

Data classification in internal knowledge management In-company software development in referrals

3. Believability

Create the necessary training in data exploitation

4. Validity

Information sampling of resources

5. Availability

Create a new method in the intelligent search

6. Security

Powerful access and plagiarism

\section{Relevancy}

Development of internal infrastructure for the maintenance

8. Value Added

Verifying of information by experts

9. Being up to date

Use of authoritative references in information classification 


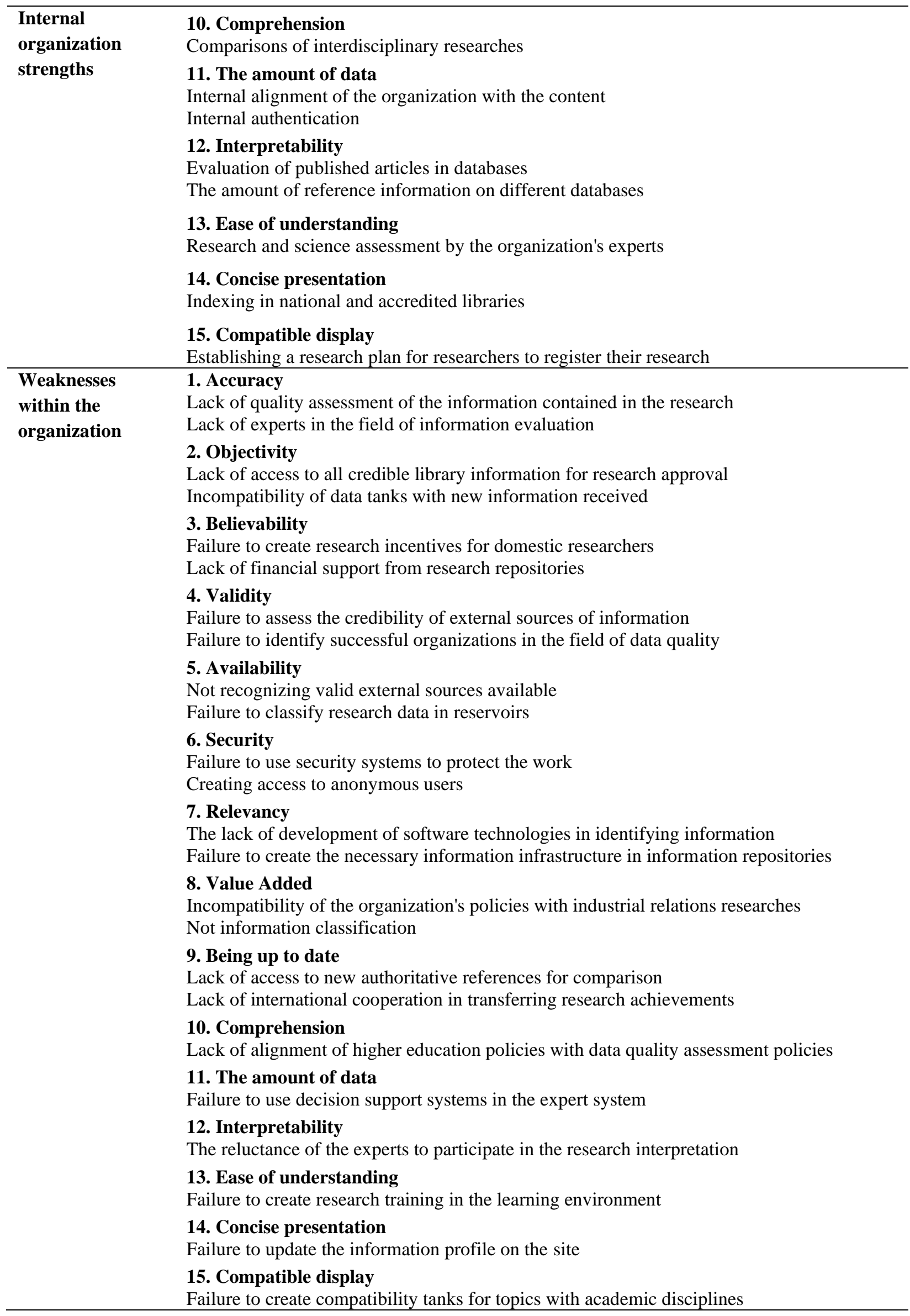

Table 3: Identification of strategies based on different dimensions of data quality. 
SWOT

\section{Strengths (S)}

Opportunities (O) SO policy:

1. Developing and classifying the appropriate space for recording, controlling, indexing and disseminating received information

2. Development of communication with authoritative databases for the appropriate dissemination of research data

3. Use of experts in research affairs to index the data

Threats (T)
1. Development of software for assessing the quality of data using experienced staff

2. Classification of research information

3. The weighting of researches based on the quality of used data

\section{Weaknesses (W)}

WO policy:

1. Establish a comprehensive knowledge repository base of all research in all universities

2. Collaborate with other knowledge databases in the classification process of information

3. Improving the comprehensive thesis/dissertation registration process at universities

4. Establish a comprehensive authentication system

WT policy:

1. Benchmarking of strong information tanks in other countries

2. Establish training courses for key personnel of the organization

3. Survey of users satisfaction

Table 4: Extracted strategies.

\begin{tabular}{|c|c|c|c|}
\hline Symbol & Strategy & Symbol & Strategy \\
\hline $\mathrm{W}_{1}$ & $\begin{array}{l}\text { Developing and classifying the } \\
\text { appropriate space for recording, } \\
\text { controlling, indexing and disseminating } \\
\text { of the received information }\end{array}$ & $W_{7}$ & $\begin{array}{l}\text { Comprehensive Authentication / } \\
\text { Integration System }\end{array}$ \\
\hline $\mathbf{W}_{2}$ & $\begin{array}{l}\text { Development of communication with } \\
\text { authoritative databases for the proper } \\
\text { dissemination of research data }\end{array}$ & $\mathbf{W}_{\mathbf{8}}$ & $\begin{array}{l}\text { Development of software for } \\
\text { assessing the quality of data } \\
\text { using experienced staff }\end{array}$ \\
\hline $\mathbf{W}_{3}$ & $\begin{array}{l}\text { The use of professors in research } \\
\text { affairs to index the data used }\end{array}$ & $W_{9}$ & $\begin{array}{l}\text { Classification of research } \\
\text { information }\end{array}$ \\
\hline $\mathbf{W}_{4}$ & $\begin{array}{l}\text { Create a comprehensive knowledge } \\
\text { base of all research in all universities }\end{array}$ & $W_{10}$ & $\begin{array}{l}\text { Weighing on research based on } \\
\text { the quality of data used }\end{array}$ \\
\hline $\mathbf{W}_{5}$ & $\begin{array}{c}\text { Collaborate with other knowledge } \\
\text { bases in the classification of } \\
\text { information }\end{array}$ & $W_{11}$ & $\begin{array}{c}\text { Bench Marking has strong } \\
\text { information repositories in other } \\
\text { countries }\end{array}$ \\
\hline \multirow[t]{2}{*}{$W_{6}$} & $\begin{array}{l}\text { Changes in the comprehensive } \\
\text { thesis/dissertation registration process } \\
\text { at universities }\end{array}$ & $W_{12}$ & $\begin{array}{l}\text { Creating training courses for } \\
\text { key personnel of the } \\
\text { organization }\end{array}$ \\
\hline & & $W_{13}$ & Use surveys of users \\
\hline
\end{tabular}

Table 5: Categorized strategies for employing BWM.

\section{Conclusion}

In this research, weaknesses, strengths, opportunities and organizational threats were discussed in the subject areas of data quality and finally 13 key components were identified as main policies for improving data quality of studied CRIS. To achieve these 13 components for augmentation of quality of CRIS, 15 different dimensions of data quality (such as accuracy, objectivity, believability, etc.) and their impact on the studied CRIS were comprehensively studied. Then, using the BWM method, effective strategies were ranked and prioritized. The results of the evaluation showed that the development and classification of the appropriate space for the recording, control, indexing and dissemination of information was given top priority. The second most important component is the creation of a comprehensive knowledge base of all research data at all universities. The organization should use the strategy under investigation to 


\begin{tabular}{|c|c|c|c|c|c|c|c|c|c|c|c|c|c|}
\hline \multicolumn{14}{|c|}{ The average weight of strategy indicators based on expert opinion } \\
\hline Weight & $\mathrm{W}_{1}$ & $\mathrm{~W}_{2}$ & $\mathrm{~W}_{3}$ & $\mathrm{~W}_{4}$ & $\mathrm{~W}_{5}$ & $\mathrm{~W}_{6}$ & $\mathrm{~W}_{7}$ & $\mathrm{~W}_{8}$ & $\mathrm{~W}_{9}$ & $\mathrm{~W}_{10}$ & $\mathrm{~W}_{11}$ & $\mathrm{~W}_{12}$ & $\mathbf{W}_{13}$ \\
\hline $\begin{array}{c}\text { The most important } \\
\text { dimension } W_{1}\end{array}$ & 1.00 & 3.6 & 4.2 & 3 & 5.4 & 4.8 & 6.2 & 4 & 4.6 & 4.8 & 4.4 & 4.2 & 4 \\
\hline
\end{tabular}

Table 6: Paired comparison vector for the best criterion.

\begin{tabular}{cccccccccccccccc}
\hline \multicolumn{11}{c}{ The average weight of strategy indicators based on expert opinion } \\
\hline Weight & $\mathrm{W}_{1}$ & $\mathrm{~W}_{2}$ & $\mathrm{~W}_{3}$ & $\mathrm{~W}_{4}$ & $\mathrm{~W}_{5}$ & $\mathrm{~W}_{6}$ & $\mathrm{~W}_{7}$ & $\mathrm{~W}_{8}$ & $\mathrm{~W}_{9}$ & $\mathrm{~W}_{10}$ & $\mathrm{~W}_{11}$ & $\mathrm{~W}_{12}$ & $\mathbf{W}_{\mathbf{1 3}}$ \\
$\begin{array}{c}\text { The most important } \\
\text { dimension } \\
\mathbf{W}_{\mathbf{9}}\end{array}$ & 4.2 & 4.3 & 5.1 & 4.2 & 6.2 & 4.7 & 6.2 & 4 & 1 & 5.2 & 4.7 & 5.2 & $\mathbf{4 . 7}$ \\
& & & & & & & & & & & & & \\
\hline
\end{tabular}

Table 7: Paired comparison vector for the worst criterion.

\begin{tabular}{ccccccccccccc}
\hline$W_{1}$ & $W_{2}$ & $W_{3}$ & $W_{4}$ & $W_{5}$ & $W_{6}$ & $W_{7}$ & $W_{8}$ & $W_{9}$ & $W_{10}$ & $W_{11}$ & $W_{12}$ & $W_{13}$ \\
\hline $\mathbf{0 . 2 0}$ & 0.08 & 0.07 & $\mathbf{0 . 1 0}$ & $\mathbf{0 . 0 6}$ & $\mathbf{0 . 0 6}$ & $\mathbf{0 . 0 5}$ & $\mathbf{0 . 0 7}$ & $\mathbf{0 . 0 2}$ & $\mathbf{0 . 0 6}$ & $\mathbf{0 . 0 7}$ & $\mathbf{0 . 0 7}$ & $\mathbf{0 . 0 7}$ \\
\hline
\end{tabular}

Table 8: Calculated weight of research criteria.

\begin{tabular}{|c|c|c|}
\hline Strategy & $\begin{array}{l}\text { The following are the } \\
\text { components of the strategy }\end{array}$ & Strategy weight \\
\hline \multirow[t]{3}{*}{ SO Policy } & $w_{1}$ & 0.35 \\
\hline & $\mathbf{w}_{2}$ & \\
\hline & $\mathbf{w}_{3}$ & \\
\hline \multirow[t]{4}{*}{ WO Policy } & $\mathbf{w}_{4}$ & 0.27 \\
\hline & $w_{5}$ & \\
\hline & $w_{6}$ & \\
\hline & $\mathbf{W}_{7}$ & \\
\hline \multirow[t]{3}{*}{ ST Policy } & $\mathbf{W}_{8}$ & 0.15 \\
\hline & $W_{9}$ & \\
\hline & $W_{10}$ & \\
\hline \multirow[t]{3}{*}{ WT Policy } & $W_{11}$ & 0.21 \\
\hline & $\mathrm{w}_{12}$ & \\
\hline & $W_{13}$ & \\
\hline
\end{tabular}

Table 9: Ranking Strategies.

drive their data quality goals. Because good data quality leads to an acceleration of digital processes, an increase in productivity and an increase in corporate success. These results are along with [47] who defined three levels of quality, based partially on the extent of documentation provided to downstream users, whether they be partners, aggregators, practitioners, or users. Application profiles, which at the most basic level document the intent of the creator of the metadata, give important clues to those outside the institution or domain of the metadata creators and are increasingly used to provide guidance to specific organizations and communities of practice. [48] defined some strategies based on data quality dimensions for improving the performance of CRIS. Trying to emulate benchmark practices, evaluating the benefits of the implemented system and finally training the users to the system are the most important strategies which are along with the results of current research.

According to the results of this research, in order to complete the obtained results, it is suggested:

1. Using the fuzzy analysis approach in decision making to increase the accuracy in organizing the organization's strategy.

2. Adding other dimensions of KM on data quality and creating a comprehensive framework of organizational strategies in the form of conceptual models. 
3. Classification of databases of articles and dissertations in the center of Iran for the classification of strategy for each of the above two main categories.

4. Using the PESTLE method (Political, Economic, Social, Technological, Legal and Environmental) to more accurately assess the opportunities, strengths, weaknesses and organizational threats.

\section{References}

[1] Azeroual, O. \& Schöpfel, J. (2019). Quality Issues of CRIS data: An exploratory investigation with universities from twelve countries. Publications, 7(1), 14.

https://doi.org/10.3390/publications7010014

[2] Ershadi, M. J., \& Aiassi, R. (2017). A Model for Quality Assurance on Acquisition and Registration, Processing, and Dissemination of Theses and Dissertations Systems. Journal of Information Technology Management, 9(2), 167-190. https://www.sid.ir/en/journal/ViewPaper.aspx $? i d=5$ 75896

[3] Waddington, S., Sudlow, A., Walshe, K., Scoble, R., Mitchell, L., Jones, R., \& Trowell, S. (2013). Feasibility study into the reporting of research information at a national level within the uk higher education sector. New review of information networking, 18(2), 74-105.

https://doi.org/10.1080/13614576.2013.841446

[4] Quix, C., \& Jarke, M. (2014). Information integration in research information systems. Procedia Computer Science, 33, 18-24.

https://doi.org/10.1016/j.procs.2014.06.004

[5] Azeroual, O., Saake, G. \& Abuosba, M. (2018). Data quality measures and data cleansing for research information systems. Journal of Digital Information Management, 16(1), 12-21.

https://arxiv.org/abs/1901.06208

[6] Azeroual, O., Saake, G. \& Schallehn, E. (2018). Analyzing data quality issues in research information systems via data profiling. International Journal of Information Management, 41, 50-56.

https://doi.org/10.1016/j.ijinfomgt.2018.02.007

[7] Chitsaz, N., \& Azarnivand, A. (2017). Water scarcity management in arid regions based on an extended multiple criteria technique. Water Resources Management, 31(1), 233-250. https://doi.org/10.1007/s11269-016-1521-5

[8] Maghsoodi, A. I., Mosavat, M., Hafezalkotob, A., \& Hafezalkotob, A. (2019). Hybrid hierarchical fuzzy group decision-making based on information axioms and BWM: Prototype design selection. Computers \& Industrial Engineering, 127, 788-804. https://doi.org/10.1016/j.cie.2018.11.018

[9] Gupta, H., \& Barua, M. K. (2018). A framework to overcome barriers to green innovation in SMEs using BWM and Fuzzy TOPSIS. Science of The Total Environment, 633, 122-139.

https://doi.org/10.1016/j.scitotenv.2018.03.173

[10] Cassidy, A. (2016). A practical guide to information systems strategic planning. CRC press. Available at:
https://www.routledge.com/A-Practical-Guide-toInformation-Systems-StrategicPlanning/Cassidy/p/book/9780849350733

[11]Dubey, S., Verma, K., Rizvi, M. A., \& Ahmad, K. (2018). SWOT Analysis of Cloud Computing Environment. In Big Data Analytics (pp. 727-737). Springer, Singapore. https://doi.org/10.1007/978-981-10-6620-7_71

[12] Batini, C., Cappiello, C., Francalanci, C., \& Maurino, A. (2009). Methodologies for data quality assessment and improvement. ACM computing surveys (CSUR), 41(3), 16. https://doi.org/10.1145/1541880.1541883

[13] Blumenberg, S., Wagner, H. T., \& Beimborn, D. (2009). Knowledge transfer processes in IT outsourcing relationships and their impact on shared knowledge and outsourcing performance. International Journal of Information Management, 29(5), 342-352.

https://doi.org/10.1016/j.ijinfomgt.2008.11.004

[14] Al-Emran, M., Mezhuyev, V., Kamaludin, A., \& Shaalan, K. (2018). The impact of knowledge management processes on information systems: A systematic review. International Journal of Information Management, 43, 173-187.

https://doi.org/10.1016/j.ijinfomgt.2018.08.001

[15] Lee, J. N. (2001). The impact of knowledge sharing, organizational capability and partnership quality on IS outsourcing success. Information \& Management, 38(5), 323-335.

https://doi.org/10.1016/s0378-7206(00)00074-4

[16] Lee, C. P., Lee, G. G., \& Lin, H. F. (2007). The role of organizational capabilities in successful e-business implementation. Business Process Management Journal, 13(5), 677-693. https://doi.org/10.1108/14637150710823156

[17] Lee, J. C., Shiue, Y. C., \& Chen, C. Y. (2016). Examining the impacts of organizational culture and top management support of knowledge sharing on the success of software process improvement. Computers in Human Behavior, 54, 462-474. https://doi.org/10.1016/j.chb.2015.08.030

[18] Spender, J. C. (1996). Making knowledge the basis of a dynamic theory of the firm. Strategic management journal, 17(S2), 45-62. https://doi.org/10.1002/smj.4250171106

[19]De Long, D. (1997). Building the knowledge-based organization: How culture drives knowledge behaviors. Ernst \& Young Center for Business Innovation, Working Paper, Boston. Available at: http://providersedge.com/docs/km_articles/Building _the_Knowledge-Based_Organization.pdf

[20] Soto-Acosta, P., Popa, S., \& Palacios-Marqués, D. (2017). Social web knowledge sharing and innovation performance in knowledge-intensive manufacturing SMEs. The Journal of Technology Transfer, 42(2), 425-440. https://doi.org/10.1007/s10961-016-9498-z

[21] Tiwana, A. (2000). The knowledge management toolkit: practical techniques for building a knowledge management system. Prentice Hall PTR. Available at: 
https://dl.acm.org/doi/book/10.5555/323909

[22] Figueiredo, M. S. N., \& Pereira, A. M. (2017). Managing knowledge-the importance of databases in the scientific Production. Procedia Manufacturing, $12,166-173$. https://doi.org/10.1016/j.promfg.2017.08.021

[23] Hoegl, M., \& Schulze, A. (2005). How to Support Knowledge Creation in New Product Development: An Investigation of Knowledge Management Methods. European management journal, 23(3), 263273.

https://doi.org/10.1016/j.emj.2005.04.004

[24] Chong, A. Y. L., Chan, F. T., Goh, M., \& Tiwari, M. K. (2013). Do inter-organizational relationships and knowledge-management practices enhance collaborative commerce adoption? International Journal of Production Research, 51(7), 2006-2018. https://doi.org/10.1080/00207543.2012.701776

[25] Lin, H. F., \& Lee, G. G. (2005). Impact of organizational learning and knowledge management factors on e-business adoption. Management Decision, 43(2), 171-188. https://doi.org/10.1108/00251740510581902

[26] Migdadi, M. M., Abu Zaid, M. K. S., Al-Hujran, O. S., \& Aloudat, A. M. (2016). An empirical assessment of the antecedents of electronic-business implementation and the resulting organizational performance. Internet Research, 26(3), 661-688. https://doi.org/10.1108/intr-08-2014-0203

[27] Turban, E., Sharda, R., \& Delen, D. (2010). Decision Support and Business Intelligence Systems $\left(9^{\text {th }}\right.$ Edition). Prentice Hall, Upper Saddle River. Available at: https://www.pearson.com/us/highereducation/product/Turban-Decision-Support-andBusiness-Intelligence-Systems-9th-Edition /9780136107293.html

[28] Mitchell, H. J. (2003). Technology and knowledge management: Is technology just an enabler or does it also add value? In Knowledge management: Current issues and challenges (pp. 66-78). IGI Global. https://doi.org/10.4018/978-1-93177-751-3.ch006

[29] Aljumaili, M., Karim, R., \& Tretten, P. (2016). Metadata-based data quality assessment. VINE Journal of Information and Knowledge Management Systems, 46(2), 232-250. https://doi.org/10.1108/vjikms-11-2015-0059

[30] Ershadi, M. J., Aiasi, R., \& Kazemi, S. (2018). Root cause analysis in quality problem solving of research information systems: a case study. International Journal of Productivity and Quality Management, 24(2), 284-299.

https://doi.org/10.1504/ijpqm.2018.10012949

[31] Collins, F. S., \& Tabak, L. A. (2014). Policy: NIH plans to enhance reproducibility. Nature, 505(7485), 612-613. https://doi.org/10.1038/505612a

[32]Li, F., Hu, J., Xie, K., \& He, T. C. (2015). Authentication of experimental materials: A remedy for the reproducibility crisis? Genes \& diseases, 2(4), 283.

https://doi.org/10.1016/j.gendis.2015.07.001
[33] Timmerman, Y., \& Bronselaer, A. (2019). Measuring data quality in information systems research. Decision Support Systems, 126, 113138. https://doi.org/10.1016/j.dss.2019.113138

[34] Ershadi, M. J., \& Forouzandeh, M. (2019). Information Security Risk Management of Research Information Systems: A hybrid approach of Fuzzy FMEA, AHP, TOPSIS and Shannon Entropy. Journal of Digital Information Management, 17(6), 321. https://doi.org/10.6025/jdim/2019/17/6/321-336

[35] Ershadi, M. J., Jalalimanesh, A., \& Nasiri, J. (2019). Designing a Metadata Quality Model: Case Study of Registration System of Iranian Research Institute for Information Science and Technology. Iranian Journal of Information processing and Management, 34(4), 1505-1534. http://jipm.irandoc.ac.ir/article-1-4091-en.html

[36] Mezghani, E., Exposito, E., \& Drira, K. (2016). A collaborative methodology for tacit knowledge management: Application to scientific research. Future Generation Computer Systems, 54, 450-455. https://doi.org/10.1016/j.future.2015.05.007

[37] Ershadi, M. J., Niaki, S. T. A., \& Sadeghee, R. (2019). Evaluation and improvement of service quality in information technology department of a detergent production company using the SERVQUAL approach. International Journal of Services and Operations Management, 34(2), 228-240. https://doi.org/10.1504/ijsom.2019.10024665

[38]Batini, C., \& Scannapieco, M. (2016). Data and information quality. Cham, Switzerland: Springer International Publishing. https://doi.org/10.1007/978-3-319-24106-7

[39] Marsden, J. R., \& Pingry, D. E. (2018). Numerical data quality in IS research and the implications for replication. Decision Support Systems, 115, A1-A7. https://doi.org/10.1016/j.dss.2018.10.007

[40] Azeroual, O., Saake, G. \& Wastl, J. (2018). Data measurement in research information systems: Metrics for the evaluation of the data quality. Scientometrics, 115(3), 1271-1290. https://doi.org/10.1007/s11192-018-2735-5

[41] Wang, R. Y., \& Strong, D. M. (1996). Beyond accuracy: What data quality means to data consumers? Journal of management information systems, 12(4), 5-33. https://doi.org/10.1080/07421222.1996.11518099

[42] Gürel, E., \& Tat, M. (2017). SWOT ANALYSIS: A THEORETICAL REVIEW. Journal of International Social Research, 10(51). Available at: https://www.sosyalarastirmalar.com/cilt10/sayi51_p df/6iksisat_kamu_isletme/gurel_emet.pdf

[43] Phadermrod, B., Crowder, R. M., \& Wills, G. B. (2019). Importance-performance analysis based SWOT analysis. International Journal of Information Management, 44, 194-203. https://doi.org/10.1016/j.ijinfomgt.2016.03.009

[44] Johansson, Å., \& Ottosson, M. O. (2012). A national Current Research Information System for Sweden. In: Jeffery, Keith G; Dvořák, Jan (eds.): E-Infrastructures 
for Research and Innovation: Linking Information Systems to Improve Scientific Knowledge Production: Proceedings of the 11th International Conference on Current Research Information Systems (June 6-9, 2012, Prague, Czech Republic), pp. 67-71. Available at:

https://dspacecris.eurocris.org/handle/11366/103

[45] Fernandes, S. (2019). Looking deep at current research information systems. Qualitative and Quantitative Methods in Libraries, 7(2), 281-291. Available at:

http://78.46.229.148/ojs/index.php/qqml/article/view 1475

[46] Rezaei, J. (2015). Best-worst multi-criteria decisionmaking method. Omega, 53, 49-57. https://doi.org/10.1016/j.omega.2014.11.009

[47] Bruce, T. R., \& Hillmann, D. I. (2004). The continuum of metadata quality: defining, expressing, exploiting. ALA editions. Available at: https://ecommons.cornell.edu/handle/1813/7895

[48] Campanella, P., Lovato, E., Marone, C., Fallacara, L., Mancuso, A., Ricciardi, W., \& Specchia, M. L. (2015). The impact of electronic health records on healthcare quality: a systematic review and metaanalysis. The European Journal of Public Health, 26(1), 60-64. https://doi.org/10.1093/eurpub/ckv122

[49]Zimmerman, E.H. (2002). CRIS-Cross: Research Information Systems at a Crossroads. CRIS2002: 6th International Conference on Current Research Information Systems (Kassel, August 29-31, 2002). Available at: https://dspacecris.eurocris.org/handle/11366/129

[50] Wenaas, L., Karlstrom, N., Vatnan, T. (2012). From a national CRIS along the road to Green Open Access - and back again: Building infrastructure from CRIStin to Institutional Repositories in Norway. CRIS2012: 11th International Conference on Current Research Information Systems (Prague, June 6-9, 2012). Available at:

https://dspacecris.eurocris.org/handle/11366/116?mo de $=$ full 